\title{
« Anime: sueños de narcisismo y omnipotencia ${ }^{1}$
}

\section{Carlos Molina Velásquez Universidad Centroamericana "José Simeón Cañas" (UCA)}

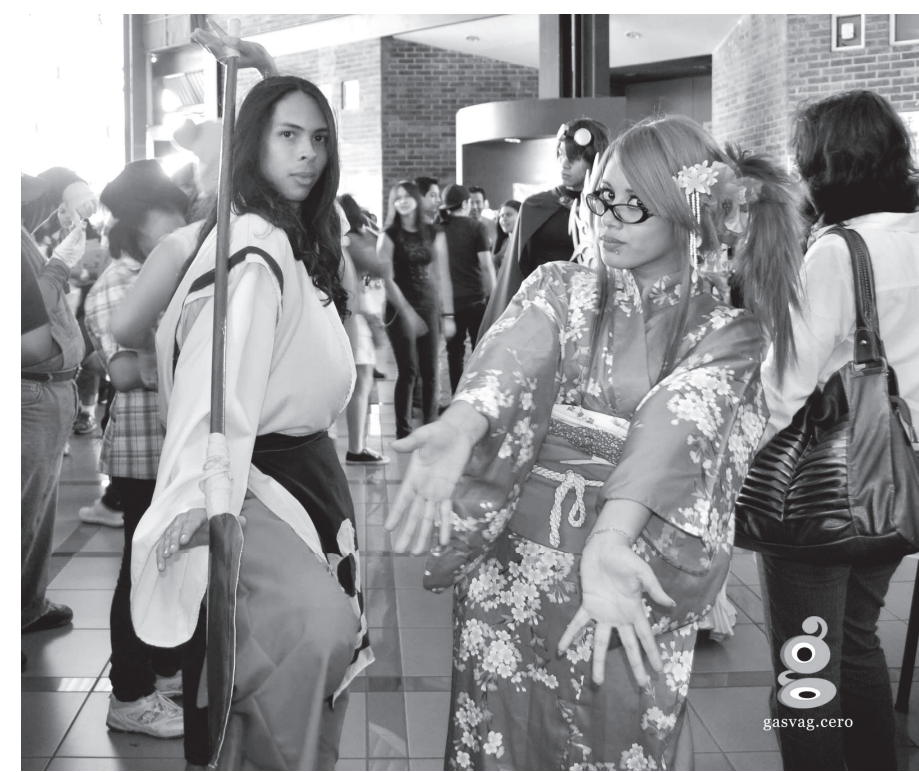

Ilustración 9. Reunión de "Yuma no Tsubsa" (Alas de un sueño), grupo de fans del Anime, en las instalaciones de la UCA, en 2011. Tomado del blog gasvag.cero

Apoyándome en mi afición al anime, análisis de especialistas ${ }^{2}$ y la crítica filosófica de Franz Hinkelammert, quiero compartir mis reflexiones sobre algunas características del género que son especialmente llamativas para las comunidades jóvenes, al mismo tiempo que social y políticamente inquietantes. La escritora salvadoreña Lauri García dice de los otaku "que se sienten parte de una caricatura japonesa" (García Dueñas y Meza Díaz, 2011, p. 121), y no deja de ser significativo que uno de sus clubes más importantes, en El Salvador, tenga por 
nombre Yume No Tsubasa:4 "Alas de un sueño". ¿De qué tipo de sueño se trata? Posiblemente, uno en el que nunca se deja de ser un niño, aunque un niño japonés (García Dueñas y Meza Díaz, 2011, p. 123). No obstante, yo veo otras figuras en esos sueños y a eso me quiero referir.

Los fanes del anime admiran héroes adolescentes. A diferencia de los superhéroes del cómic estadounidense, cuya "juventud" es generalmente irrelevante, los protagonistas de las historias japonesas son adolescentes que luchan para crecer y madurar, al mismo tiempo que salvan el mundo. Los héroes del anime comparten ciertos rasgos esenciales: son jóvenes, individualistas, portadores de poderes especiales y generadores de cambios positivos para la sociedad. Son modelos que gustan a los llamados millennials, ${ }^{5}$ cuya visión de la política comparte los valores otaku: la juventud es vista como una "virtud política"; el político virtuoso posee una inteligencia superior 0 habilidades "excepcionales"; y ambas cosas se expresan, políticamente, mediante la generación de discursos y prácticas novedosas. ${ }^{6}$

La política millennial es fiel al axioma "las virtudes individuales generan virtudes públicas", sustentada en la confianza en una tecnología que permite hacer el traslado. En el fondo, esto es así porque la idea que se tiene de las organizaciones políticas - los partidos, principalmente- es generalmente negativa y se tiende a confiar en demasía en la eficacia de mecanismos que generen "consensos rápidos", aunque sean generados por la mera suma de puntos de vista y no por el debate y los acuerdos.

Si en el anime los héroes poseen diversas variedades y grados de omnipotencia, en la visión política millennial toda la confianza se deposita en el inusual poder de una personalidad bien cultivada, pero también en la lucha política que se hace sin la necesidad de construir vínculos con otros. Esta audaz combinación de superioridad moral y misantropía no es la excepción, sino lo usual en el anime, incluso cuando la camaradería es parte de la sustancia de la trama. Pero lo fundamental reside en una trampa oculta bajo el axioma de las virtudes: la máquina que transforma las virtudes individuales en beneficios colectivos es la "serpiente moderna”, mano invisible y método de armonización que exige, como pago, la renuncia a nuestra humanidad. No podríamos esperar algo diferente de una política sin lazos humanos, pero cargada de cadenas: la confianza en una política tecnócrata se lleva de maravilla con el autoritarismo y el elogio de la sumisión que vemos aparecer, una y otra vez, en el anime.

Los rasgos que he descrito muestran su rostro más oscuro, el del posthumanismo, en la película 
Akira $^{7}$ - de 1988-, considerada un clásico del anime, que nos presenta, en palabras de Franz Hinkelammert: "un mundo dominado por la paranoia de la omnipotencia de un narcisismo total" (Hinkelammert, 1995, p. 322, nota 12). ${ }^{8}$ Los héroes de Akira -Kaneda y Tetsuo, jóvenes miembros de una pandilla de motociclistas que luchan en las calles de un Tokio postapocalípticoposeen las virtudes necesarias para vencer la fatalidad social, que en la historia es representada por una alianza de científicos, militares y burócratas, los cuales, mediante la combinación de orden tecnológico y caos social, esperan evitar que se repita la espantosa destrucción que ocurriera años atrás $-y$ que fuera provocada por ellos mismos-. Frente a este orden injusto, aquellas virtudes juveniles de los dos amigos -tenaz impulso de conservación, rebeldía ante lo establecido y camaradería implacable - y sus correspon- dientes vicios - pulsión de muerte, rechazo de toda ley y violencia que desemboca en el "asesinato del hermano"- funcionan como detonadores de lo nuevo, o lo que es igual, devienen en absoluto terror.

Es destacable la forma como se imagina la transformación del orden despótico vigente en un nuevo orden: mediante la "disolución de la individualidad", que no se consigue mediante la comunicación y las relaciones intersubjetivas, sino gracias a la renuncia a la misma humanidad y la aceptación de la verdad biológica del determinismo evolutivo. Este nuevo darwinismo social desembocará, naturalmente, en la aniquilación total de lo humano. La ciudad destruida, en la secuencia final, carece de vida; incluso los rayos de sol que asoman entre las nubes parecen estar muertos. Sobre esto, advierte Hinkelammert:

\begin{abstract}
Akira es el omnipotente, cuyo poder se muestra por el hecho de que por un puro acto de voluntad logra destruir Tokio entero. Se transforma en un Mesías, que es el "iluminado" que no promete ningún reino mesiánico. Es el "iluminado" porque nadie tiene un poder igual [al de] él. Otros buscan derrotarlo, pero desean su derrota para asumir su lugar. No existen solidaridades. Por ende, todos se desvanecen en la destrucción mutua (Hinkelammert, 1995, p. 322, nota 12).
\end{abstract}

Esto es válido para déspotas y rebeldes. Los científicos, militares y burócratas corruptos causaron el horror, pero sus antagonistas son también cómplices de una vergon- zosa afinidad: Kei, la joven rebelde, políticamente correcta e inteligente, podrá inclinar la balanza hacia una incipiente justicia, pero antes tendrá que "renunciar a su conciencia" 
y convertirse en marioneta de "los números", niños-sujetos experimentales con superpoderes, cuyo elocuente nombre nos recuerda los íntimos lazos entre el desarrollo tecnológico y la disposición a cometer actos de barbarie.

Por su parte, la apocatástasis del final de la historia es más una pesadilla que un sueño: una paz sin esperanza y sin futuro, conseguida mediante la renuncia a lo que nos hace humanos. Lo que ahora "gobierna" a los hombres y mujeres que caminan tambaleantes sobre la tierra yerma es algo totalmente otro. Esta alteridad monstruosa no es otra que Akira-Tetsuo, ${ }^{9}$ el omnipotente que, como veíamos antes, no promete absolutamente nada: el dios posthumano perfecto para un mundo postpolítico. ${ }^{10}$

Así como en Akira, hay tres animes en los que destacan los delirios mesiánicos y un insaciable deseo de aniquilación. El primero es, naturalmente, Neon Genesis Evangelion ${ }^{11}$-que se comenzó a emitir en 1995-, considerada por muchos como la mejor serie jamás creada, entre otras cosas, porque logró interesar a un público que, hasta entonces, consideraba al anime un género poco serio. La peculiar mezcla de robots, símbolos judeocristianos y thriller psicológico supo combinar con maestría los dos elementos típicos del género, a los que ya me he referido: el "drama adolescente" y la salvación del mundo, 12 nuevamente, en un escenario postapocalíptico. ${ }^{13}$

En la historia, el mal adopta la forma de "ángeles", portadores de la total destrucción de la humanidad. La defensa contra esta amenaza la dirige una organización paramilitar, la cual confía sus mejores armas - los robots tripulados conocidos como EVA- a tres adolescentes, entre los que destaca el inseguro y psicológicamente inestable Shinji Ikari, hijo del despótico líder de la organización, quien además lo trata con displicencia y crueldad. Como era de esperarse, el "asunto edípico" en el personaje ha sido ampliamente analizado - su odio al padre que lo abandonó, la necesidad de luchar contra él, entre otros-, pero la tragedia de Shinji no tiene por qué ser vista únicamente bajo la lente freudiana; es más, quizá deberíamos invertirla. Recurriendo a Franz Hinkelammert, podremos reparar en que el asesinato fundante del padre, que constituye la base del mito de Edipo, suele usarse para legitimar o encubrir el sacrificio necesario de los hijos. En nuestras sociedades, parece que las soluciones a los problemas de convivencia exigen la muerte de los miembros más jóvenes: "Todo el mito está concebido desde el derecho del padre de matar a su hijo. El mito encubre eso, sosteniendo la profecía según la cual el padre mata al hijo porque sabe que el hijo lo matará a él" (Hinkelammert, 2000, p. 22). 
¿No es esto lo que vemos, en realidad, en Evangelion? No importa quiénes vivan o mueran, al final, las víctimas son siempre los adolescentes pilotos de los EVA, cuya creciente culpabilidad, potenciada por hábiles estrategias de manipulación, los convierte en eficaces asesinos. Su camino hacia el descubrimiento de su propia identidad - el drama adolescente típico - está sembrado de muerte y destrucción, porque cada uno proyecta sus propios monstruos sobre el lienzo de "su yo", y solo alcanzarán su autorrealización mediante la disolución de su individualidad. Al mismo tiempo, la humanidad sólo podrá vencer las amenazas de los ángeles y alcanzar la paz al lograr la fusión de todas sus diferencias y especificidades en un todo homogéneo: el llamado proyecto de complementación humana o proyecto de instrumentalidad -o instrumentación- humana.

Pero, ¿qué es este proyecto sino un inmenso acto sacrificial? $\mathrm{Y}$, ¿de qué clase de sacrificio se trata? No es ningún salto en el vacío religioso o esotérico, sino un muy bien calculado proyecto, es decir, un sacrificio de carácter racional, donde el ser humano y los individuos pasan a ser piezas de una máquina política que termina por disolver sus miserables e insignificantes existencias -así son presentadas, una y otra vez, las individualidades de los pilotos de los EVA-, creando algo "nuevo y perfecto". Los paralelos pueden ser interesantes: así como Rei Ayanami, la primera piloto del EVA, se diluye finalmente en el todo y la nada, la preciosa individualidad millennial parece destinada a ser tragada por la máquina postpolítica que se nutre de ella, pues el que se mantenga funcionando gracias a la sangre joven no significa, desde luego, que las vidas de los jóvenes de carne y hueso le interesen en absoluto.

Una década después de Evangelion, la serie Death Note -emitida del 2006 al 2007- volvió a atraer la atención hacia el anime, incluso más allá de los círculos otaku. La historia trata de un estudiante que encuentra un libro peculiar, en el cual basta con escribir el nombre de alguien, mientras se visualiza mentalmente su rostro, para que muera. Tres rasgos caracterizan a Light Yagami, el protagonista: su conciencia de poseer una cierta superioridad moral -justificada mediante la convicción de que es el mejor estudiante de su clase y quizá de todo Japón-, su permanente aburrimiento y su convicción de que el mundo está podrido y necesita de una regeneración. Ya en el primer capítulo, Light manifiesta su real motivación: convertirse en el dios de un mundo liberado del mal mediante la pena capital.

Si en el caso de Shinji la pureza era el requisito para ser un asesino eficaz, en el caso de Light encontramos la virtud del genio, que lo convierte en el destinatario ideal - 
aunque accidental - del arma soñada.

Pero lo accidental es engañoso: también el shinigami-demonio de la muerte japonés- que le puso al alcance el cuaderno de la muerte, lo hizo porque estaba aburrido. $Y$, ¿no es el tedio tra característica típica de los mille- nnials, para quienes incluso la lucha política debe ser "entretenida"?

Ahora bien, para entender la cuestión fundamental planteada en Death Note, me quiero apoyar en la idea hinkelammertiana de la "proyección de monstruos":

En la imagen en el espejo aparece que los otros, nuestros enemigos, son monstruos. Lo son tanto, que únicamente se puede luchar contra ellos transformándose asimismo en monstruo. En consecuencia, todo es lícito frente a ellos. Todo lo que se hace frente a ellos, está bien hecho; vale decir, la sangre vertida no deja ninguna mancha. De este modo, quien hace la proyección del monstruo, resulta ser él mismo un monstruo que no conoce límites (Hinkelammert, 2003, p. 70).

Para luchar contra el monstruo -el crimen, la corrupción-, hay que convertirse en monstruo también. Esta noción está presente a lo largo de toda la trama y pienso que su lugar preeminente corresponde perfectamente a los rasgos que adopta la lucha contra la criminalidad en la sociedad contemporánea $-\mathrm{y}$, particularmente, en la imaginación millennial-, para la cual todo enemigo del orden es llamado terrorista, monstruo o animal. Light, el justiciero de la historia, es una perfecta imagen del pacto con este demonio, que consiste en la aplicación de una ley absoluta, la cual no reconoce rostros humanos, pues sólo ve ante sí puros monstruos.

Contemporánea de Death Note (2006-2007), la serie Code Geass cuenta la historia -en un mundo alternativode la rebelión de un grupo de patriotas japoneses contra la dominación de un imperio extranjero cuasi todopoderoso, liderados por un estudiante brillante, Lelouch Lamperouge, que en realidad es un príncipe renegado, hijo del emperador invasor. Lelouch, cuyo nombre de batalla es Zero, es el héroe que posee un poder especial, el arma postpolítica por excelencia: el Geass, un "artilugio" misterioso que permite controlar la conciencia de la "personaobjetivo". El control del otro se lleva al límite de la anulación de su subjetividad y la justicia -y justificación-del proyecto de liberación que es sustituida por la eficacia absoluta. Esta eficacia, como podemos imaginar, genera escenarios de aniquilación que cuestionan gravemente la legitimidad moral de la lucha.

En Code Geass, un rasgo de la conciencia política millennial se 
expresa en un malestar parecido al hastío de Light, en Death Note, pero de otro tipo: a Lelouch le produce asco y repulsión la indiferencia de sus conciudadanos ante la tiranía. En este anime, ya aparece una crítica explícita a las masas juveniles modernas atrapadas en el círculo vicioso del consumo y la atracción por el "espectáculo".

No obstante, la cuestión de fondo es un viejo problema político que las izquierdas y los movimientos de liberación han debatido ampliamente, pero que con el ascenso de la "tecnofilia" millennial se puede abordar de una forma renovada: la cuestión de si debemos luchar pactando con el poder que brinda la tecnología o si deberíamos renunciar a él, para que la obsesión con el éxito no nos impida hacer lo que debemos hacer. Una vez más, recurro a Franz Hinkelammert, quien en un libro reciente señala que:

Sigue siendo válido que el sentido de la acción frente a la amenaza de la catástrofe no está en el éxito, está en la acción misma. Y la condición para tener éxito es esa. La única acción que hoy puede tener éxito es la que no busca el sentido de la acción en el éxito. Porque, frente a las amenazas, el cálculo paraliza, las probabilidades de fracasar son muy grandes, el sistema es enorme y sumamente complejo. Entonces el sentido está en la acción, y no en el cálculo del éxito [...] Y ahí, paradójicamente, se hace posible el éxito (Hinkelammert, 2012, p. 170).

Pienso que lo que necesita nuestra política es eso que Lelouch no es capaz de ver ni asir ni entender: la mirada del otro que nos humaniza. El poder del príncipe rebelde -el Geass- sólo es posible si hay contacto visual con otra persona, pero al lograr su propósito, esa ya no es más una persona, sino un objeto de su voluntad. Así, su éxito es, al mismo tiempo, su fracaso.

La posibilidad de que los rasgos analizados sean parte del "atractivo político del anime" no debería dejarnos indiferentes. Para comprender e intervenir, necesi- tamos estudios sociológicos y psicológicos sobre su influencia en los jóvenes centroamericanos, sobre la relación potencial entre estas historias y las virtudes e ideas políticas vigentes. Sin embargo, la supuesta originalidad política de los jóvenes otaku - y también la de los llamados millennials - podría no ser tal. Si vemos hacia atrás en esta exposición, encontramos a la vieja racionalidad instrumental que reduce lo político a mera gestión de riesgos y beneficios, pura obsesión con "el éxito"; observamos la lógica suicida del cumplimiento de la ley que convierte a los demás en monstruos; y vimos cómo 
la lucha por la transformación social es convertida en rechazo de lo más genuinamente humano, en aras de una humanidad otra, algo aún mejor que nosotros mismos, pero que nos amenaza con una radical desolación. Cada una de estas historias describe, de diferentes formas, la sustitución de la comunidad política por una máquina despótica y el extravío del gesto humano en un océano de luchas sin fin.

Y entonces, ¿no será que la "política millennial" es el rostro "renovado" del viejo capitalismo? Recientemente, un columnista decía que "si [los millennials] quieren pertenecer a la condición humana, [que] empiecen por usar sus ideas y sus herramientas tecnológicas, que aprendan a hablar de frente y cierren el circuito del autismo" (Navalón, 13 de junio de 2017). Pero, ¿no es ingenuo o poco responsable pensar que "sus ideas y herramientas" son suyas, y no del sistema capitalista, que se ve en aprietos cuando, precisamente, nos atrevemos a hablar de frente y a salir del círculo autista del consumo tecnológico? El problema no son "los millennials" o "los otaku", sino aquello hacia lo que miran: nuestro capitalismo, su narcisismo y sus delirios de omnipotencia. ${ }^{14}$

\section{Referencias bibliográficas}

- Berardi, F. (7 de julio de 2017). ¿Es política la generación millennial? Eldiario.es. Recuperado de https://www.eldiario.es/interferencias/millennials-politica-precariedad_6_662543740.html

- Canacas Maradiaga, I. B; Jovel Rodríguez, D. E. y Romero Vanegas, J. A. (2016). Estudio sobre los intereses, necesidades y hábitos de consumo de los millennials salvadoreños (Tesis de pregrado), Universidad Centroamericana "José Simeón Cañas", San Salvador, El Salvador.

- Clements, J. \& McCarthy, H. (2001). The Anime Encyclopedia. A Guide to Japanese Animation since 1917. Berkeley, USA: Stone Bridge Press.

- García Dueñas, L. y Meza Díaz, F. (2011). Tribus urbanas. San Salvador: Centro Cultural de España en El Salvador.

- Gutiérrez-Rubí, A. (Junio de 2015). La generación Millennials y la nueva política. Revista de Estudios de Juventud (108), pp. 161-169. Recuperado de http://www.injuve.es/sites/default/files/2017/46/publicaciones/ revista108_12-generacion-millennials-y-la-nueva-politica.pdf . (19 de abril de 2014). La política y la Generación Millennials. El País. Recuperado de https://blogs.elpais.com/micropolitica/2014/04/ la-politica-y-la-generacion-millennials.html 
- Hinkelammert, F. J. (1995). Cultura de la esperanza y sociedad sin exclusión. San José, Costa Rica: DEl.

- (2003). El asalto al poder mundial y la violencia sagrada del imperio. San José, Costa Rica: DEl. - (2000). La fe de Abraham y el Edipo occidental. San José, Costa Rica: DEI. . (2012). Lo indispensable es inútil. Hacia una espiritualidad de la liberación. San José, Costa Rica: Editorial Arlekín.

- Murakami, T. (2005). Little Boy. The Arts of Japan's Exploding Subculture. New York/New Haven: Japan Society/Yale University Press.

- Napier, S. J. (2005). Anime from Akira to Howl's Moving Castle: experiencing contemporary Japanese animation. New York, USA: Palgrave Macmillan. . (2001). Anime from Akira to Princess Mononoke: experiencing contemporary Japanese animation. New York, USA: Palgrave Macmillan.

- Navalón, A. (13 de junio de 2017). "Millennials": dueños de la nada. El País. Recuperado de http://elpais.com/elpais/2017/06/11/ opinion/1497192510_685284.html

- Poitras, G. (2001). Anime Essentials: Every Thing a Fan Needs to Know. Berkeley: Stone Bridge Press.

- Sánchez Navarro, J. (2003). Nuevas formas de imaginar los monstruos del capitalismo globalizado: La animación japonesa en la década de los noventa. En Costa, J. y otros. El principio del fin. Tendencias y efectivos del novísimo cine japonés (pp. 229-248). Barcelona: Ediciones Paidós.

\section{Notas}

1 Ponencia leída el 12 de julio de 2017, en el VI Congreso Centroamericano de Estudios Culturales. Debates Culturales: Memoria e Interculturalidad, organizado por el Instituto de Historia de Nicaragua y Centroamérica, en la Universidad Centroamericana, Managua.

2 Para un vistazo general, ver Poitras (2001). Un buen estudio crítico lo encontramos en Napier (2005). En la primera edición de Napier (2001) hay un interesante apéndice sobre la recepción del anime en los países occidentales (pp. 239-256). Finalmente, en español, remito a Sánchez Navarro (2003).

3 Sobre la complejidad del término y su evolución, ver Murakami (2005, pp. 132-134, 164-185).

4 Recuperado de http://frikisismo.com/ resena-la-yume-no-tsubasa-2018/

5 Nacidos entre 1981 y 1996, como se explica en Gutiérrez-Rubí (2015, p. 161). Para otros, el término indica a 
los nacidos entre 1980 y 2000 . En cualquier caso, estas discrepancias no son relevantes para lo que quiero exponer.

6 Para formular mi visión de "la política millennial", he tomado en cuenta con reservas - algunos elementos presentes en los análisis de Berardi (2017); Gutiérrez-Rubí (2015); Gutiérrez-Rubí (2014) y Navalón (2017). Sobre los millennials salvadoreños y su casi nulo interés en la política, ver Canacas Maradiaga, Jovel Rodríguez y Romero Vanegas (2016, pp. 21-38, 413-448).

7 Pueden consultarse los análisis de Clements (2001, p. 9); Murakami (2005, pp. 48-51, 107-112) y Sánchez Navarro (2003, pp. 236-239).

8 Aunque Hinkelammert se refiere directamente al manga, su análisis es válido para el anime.
9 Para un sugerente análisis de los rasgos de Tetsuo, ver Napier (2005, pp. 39-48).

10 Hay una interpretación similar en Murakami (2005, pp. 147-148).

11 Ver Clements (2001, pp. 116-117); Murakami (2005, pp. 88-95, 127-132) y Sánchez Navarro (2003, pp. 240-242).

12 Por supuesto, la historia puede ser analizada de muchas maneras, como puede verse en Napier (2005, pp. 96-102).

13 Para un interesante análisis de lo apocalíptico, tanto en Akira como en Evangelion, se puede consultar a Napier (2005, pp. 249-274).

14 Para una crítica de la idoneidad del término "millennial" y un enfoque mejor informado del problema de la política en los jóvenes contemporáneos, ver Berardi (2017). 